\title{
Князев Д.А. \\ Скоростной контроль сварных рельсовых стыков железнодорожного пути Эхолокационным методом ультразвукового контроля рельсов
}

\author{
ГУП «Московский метрополитен»
}

(Россия, Москва)

doi: $10.18411 / \mathrm{sr}-10-10-2017-04$

idsp: 000001:sr-10-10-2017-04

\section{Аннотация}

Рассмотрены проблемы, возникающие при выявлении дефектов в рельсе при скоростном и ручном ультразвуковом контроле, железнодорожного транспорта как в РФ. Проведён анализ пропуска дефектных мест в рельсе на основе официальных данных РЖД. Предложены совокупность практических приёмов для устранения выявленных причин и система действий, применяемая при ультразвуковом контроле.

Уделено внимание рассмотрению теоретических вопросов, а именно распространению ультразвуковых колебаний в упругой среде.

Рассмотрено практическое применение предлагаемого метода в промышленных масштабах, исследованного в режиме лабораторных эксплуатационных испытаний.

На основе анализа применения предлагаемого метода показана его эффективность, с аналогичными методами ультразвукового контроля.

Ключевые слова: рельс, метод, сварной рельсовый стык, ультразвуковые колебания, эхо-сигнал, пьезоэлектрический преобразователь, Эхолокационный метод ультразвукового контроля, вертикальный, вертикально ориентированный горизонтальный и горизонтально ориентированный отражатель, угол ввода, угол приёма, совмещённый, раздельно-совмещённый, раздельный режим работы, Зеркальноэхотеневой способ, эффективность и достоверность контроля.

Рельс, являясь контактным элементом с колесом подвижного состава и элементов верхнего строения железнодорожного пути, подвергается постоянному механическому, химическому, динамическому и иному воздействию. Вследствие динамического воздействия колёс подвижного состава на железнодорожные рельсы, отступления от технологии производства рельсов, нарушения требований инструкций по текущему содержанию пути, нарушений технологии сварки рельсов, коррозии рельса и других причин, рельс по всему сечению испытывает максимальные нагрузки и в связи с этим в нём по всему сечению возникают большое количество разнообразных дефектов.

Поскольку в зоне сварки металл меняет свою структуру с уменьшением пластичности, хрупкой прочности и твёрдости, зона сварного стыка является локализованной неоднородностью, то есть концентратором напряжений. Поэтому заключительной операцией производства сварных рельсовых стыков является - их дефектоскопия [1].

Методы неразрушающего контроля, применяемые в схемах прозвучивания для сплошного ультразвукового контроля рельсов, например

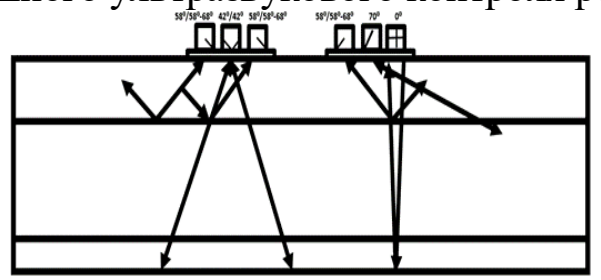

Схема прозвучивания применяемая на дефектоскопе УДС2-114 Авикон-11 ОАО «Радиоавионика»

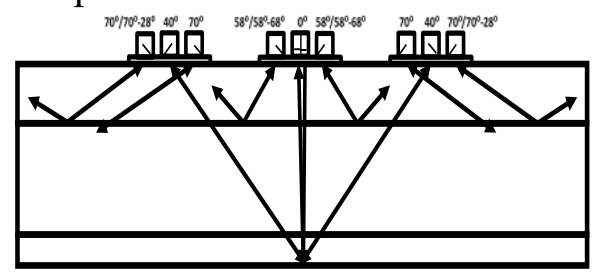

Схема прозвучивания применяемая на дефектоскопе «ИРМА «ТВЕМА» 
в полной мере не обеспечивают требуемой эффективности контроля.

Так, от общего числа допущенных изломов с 2009 по 2015 годы, в среднем 32.3\% составляют изломы в зоне сварного рельсового стыка. Из них вертикальные и вертикально ориентированные дефекты составляют - $79.8 \%$ от общего количества допущенных изломов, а горизонтальные и горизонтально ориентированные $20.2 \%$.

По всему сечению, рельс, проверяется только на предприятиях, изготавливающих рельсы - приёмочный контроль, на рельсосварочных предприятиях и операторами дистанции пути рельс проверяется локально, только в зоне сварного рельсового стыка съёмными и ручными средствами НК [1]. При эксплуатационном контроле, мобильными и съемными средствами НК проверяется только головка, шейка и её проекция в подошве рельса

С целью регистрации разноориентированных отражателей по всему сечению рельса был применен Эхолокационный метод УЗК (Патент 2442152, Рисунок 2).

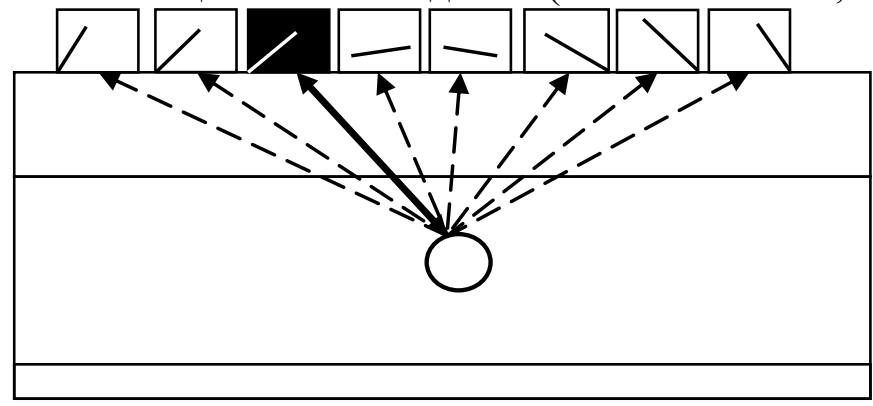

Эхолокационный метод ультразвукового контроля изделия по всему сечению применительно к рельсовой дефектоскопии (часть траектории распространения УЗК) [10]

Рисунок 2

Метод основывается на явлении рассеивания УЗК в однородной среде.

Принцип заключается в излучении в контролируемое изделие коротких зондирующих импульсов, возбуждающих в нём УЗК пьезоэлектрическим преобразователем, работающим в совмещённом или в раздельном режиме излученияприёма УЗК. Регистрация эхо-сигналов основывается, на приёме с поверхности сканирования множеством ПЭП, работающих в раздельном режиме работы в режиме приёма ЭС возбуждённых различными видами акустических волн на границе раздела сред.

При наклонном падении акустической волны происходят процессы отражения, преломления, трансформации (Рисунок 3). Каждая волна, возмущая среду, описывает поля распространения и рассеивания в широком интервале углов, то есть создаёт объёмное звуковое поле. Это звуковое поле состоит из множества звуковых полей. Основу звукового поля составляют геометрические поля, состоящие из траекторий описанных законами геометрической оптики, которые связываются между собой дифракционными полями, не допуская разрывов в звуковом поле.

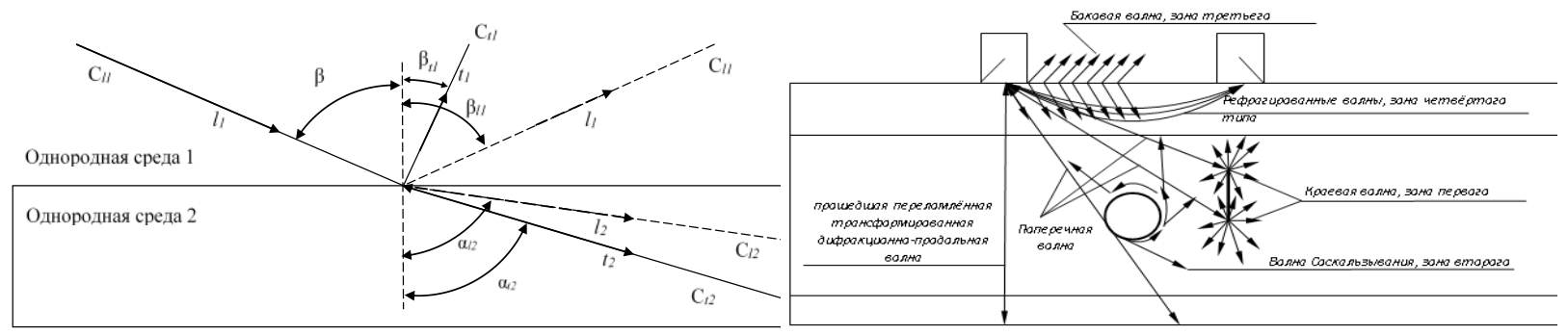

Схема образования продольной «l» и поперечной «t» волны на гранииу раздела двух сред по закону Снеллиуса [11]

Дифракционные зоны первого, второго, третьего, четвёртого типа, возбуждаемые при наклонном вводе ультразвуковых колебаний [3] 
Волны дифракции, распространяясь в разных направлениях, проникают в озвучиваемую область и интерферируют в ней с отражёнными и преломлёнными волнами описываемыми законами геометрической оптики, образуя суммарное поле в объекте контроля [3] позволяя реализовать различные способы Эхолокационного метода УЗК (ЭЛМ УЗК).

Так как дефекты разноориентированы, озвучивание необходимо производить, чтобы акустические поля, создаваемые ПЭП излучающими и принимающими УЗК, пересекались друг с другом, создавая тем самым звуковой коридор для сканирования всего сечения.

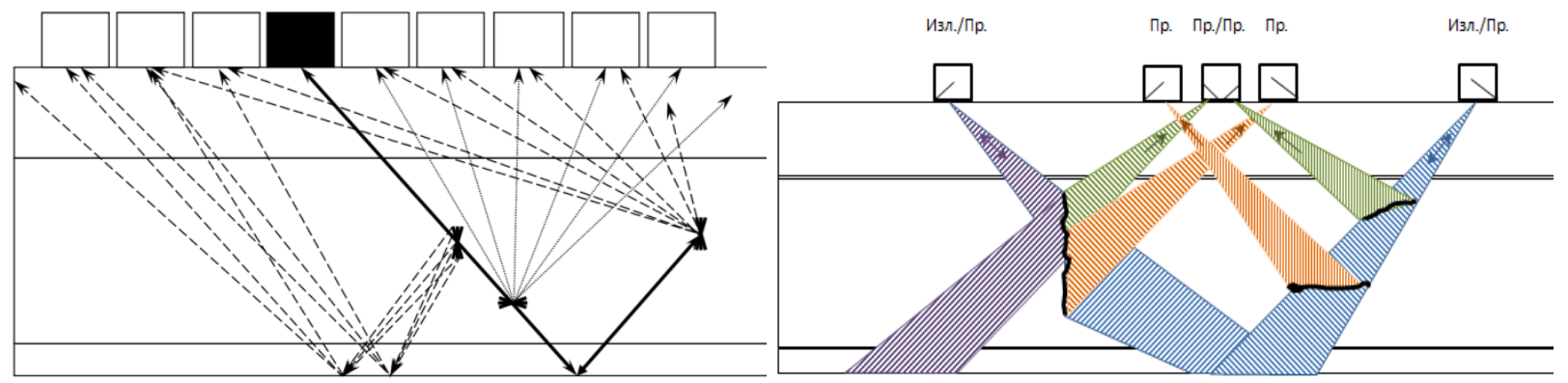

Зеркальноэхотеневой способа реализаџии Эхолокащионного метода ультразвукового контроля изделия по всему сечению применительно к рельсовой дефектоскопии (часть траектории распространения УЗK)

Рисунок 4

Способ реализации ЭЛМ УЗК, заключатся в регистрации ЭС возбуждённых поперечной волной «t2» отражённой от вертикальных, вертикально ориентированных, горизонтальных и горизонтально ориентированных отражателей, расположенных в проекции плоскости распространения УЗК, множеством наклонных ПЭП, работающих в раздельном режиме работы в режиме приёма, акустические оси диаграмм направленности которых лежат в одной вертикальной плоскости с излучающим ПЭП и в зависимости от положения отражателя направленных либо в одном направлении с акустической осью ПЭП-излучателя либо в противоположном направлении, размещённых на расстоянии Bп1=2htgkt2 [4] для регистрации однократно отражённых ЭС от горизонтальных и горизонтально ориентированных отражателей, Вп2=(2Htgat2)-(2htgkt2) [5] для регистрации двукратно отражённые ЭС от вертикальных и вертикально ориентированных отражателей, ВП3=(2Htgat2)+((2Htgat2)-(2htgkt2)) [5] для регистрации трёхкратно отражённых ЭС от горизонтальных, горизонтально ориентированных отражателей, между излучающим ПЭП и принимающими ПЭП.

Интегрируя возможность ПЭП одновременно регистрировать однократно и двукратно отражённые ЭС от горизонтальных, горизонтально ориентированных, вертикальных и вертикально ориентированных отражателей, в схемах прозвучивания при сплошном контроле мобильными, съемными и ручными средствами НК, ЭЛМ УЗК возможно реализовать различными вариантами компоновки.

Для проведения испытаний использовались дефектоскоп «ЭХО-КОМПЛЕКС»с ПО «КРУЗ-М ХР» и дефектоскоп «ЭХО-КОМПЛЕКС-2» с ПО «КРУЗ-2» и искательная лыжа с тремя искательными блоками по три ПЭП. С учётом количества каналов (6 или 9 каналов на одну нитку) и конструкционных размеров между ПЭП в искательной лыже была составлена «V-образная» схема прозвучивания (Рисунок № 5) реализующая Зеркальноэхотеневой способ реализации Эхолокационного метода УЗК (ЗЭТС ЭЛМ УЗК).

Проведены лабораторные испытания в режиме ручного и сплошного контроля съёмным средством НК, эксплуатационные испытания в режиме сплошного контроля мобильными средствами. Расчёт углов «at2» «kt2» произведён по формуле Bп2=(2Htgat2)-(2htgkt2), для регистрации отражателей на глубине (h) 45-75мм двукратно 
отражённым лучом угол приёма «kt2» составил $51^{\circ}$, для отражателей на глубине (h) 85 115 мм двукратно отражённым лучом угол kt2 составил $36^{\circ}$, для отражателей на глубине (h) 120-155мм двукратно отражённым лучом угол kt2 составил $32^{\circ}$, для регистрации донной поверхности однократно отражённым лучом использованы ПЭП с углом $\alpha \mathrm{t} 240^{\circ}$ (Bп1=2Htgat2). Но так как для рельсовой дефектоскопии производятся ПЭП с минимальным углом ввода $40^{\circ}$, они и были установлены с учётом углов раскрытия диаграмм направленностей. Все испытания проводились с обоими комплектами дефектоскопного оборудования для анализа применимости способа в зависимости от уровня техники.

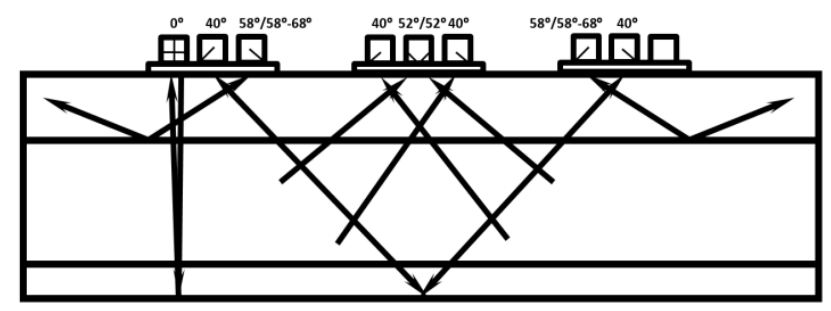

Рисунок 5

Испытания показали:

Испытания Зеркальноэхотеневого способа реализации Эхолокационного метода УЗК по регистрации моделей дефектов и натуральных дефектов, изъятых из железнодорожного пути

\begin{tabular}{|c|c|c|}
\hline Код дефекта & ЭМ УЗК & $\begin{array}{l}\text { ЗЭТС ЭЛМ } \\
\text { УЗК }\end{array}$ \\
\hline $\begin{array}{c}\text { модель дефекта 55, 56: поперечный пропил в виде сегмента в шейке } \\
\text { рельса, хорда A-32мм, глубина-6,5мм, h1-121 мм, h2-153мм }\end{array}$ & - & + \\
\hline $\begin{array}{c}\text { модель дефекта 55, 56: поперечный пропил в виде сегмента в шейке } \\
\text { рельса, хорда А-28мм, глубина-5,5мм, h1-88мм, h2-116мм }\end{array}$ & - & + \\
\hline $\begin{array}{c}\text { модель дефекта 55, 56: поперечный пропил в виде сегмента в шейке } \\
\text { рельса, хорда А-32мм, глубина-6мм, h1-44мм, h2-76мм }\end{array}$ & - & + \\
\hline код дефекта 55: $\Delta \mathrm{X}-18 \mathrm{Mм}, \Delta \mathrm{L}-140 \mathrm{Mm}, \Delta \mathrm{h} 1-95 \mathrm{MM}, \Delta \mathrm{h} 2-95 \mathrm{Mм}$ & + & + \\
\hline код дефекта 55: $\Delta \mathrm{X}-18 \mathrm{Mm}, \Delta \mathrm{L}-70 \mathrm{Mm}, \mathrm{h} 1-98 \mathrm{Mm}, \mathrm{h} 2-98 \mathrm{Mм}$ & + & + \\
\hline $\begin{array}{c}\text { модель дефекта 66, 69: сверление в подошве с центром на } \\
\text { продольной оси рельса, Ø 8мм, глубина-7мм }\end{array}$ & + & + \\
\hline $\begin{array}{c}\text { модель дефекта 52, 55, 56: горизонтальный пропил в шейке, L- } \\
\text { 40мм, глубина-8мм, h-100мм }\end{array}$ & + & + \\
\hline $\begin{array}{c}\text { модель дефекта 52, 55, 56: горизонтальный косой пропил в шейке } \\
\text { от торца, L-40мм, глубина-8мм, h-50мм }\end{array}$ & + & + \\
\hline $\begin{array}{c}\text { модель дефекта 66, 69: поперечный пропил в виде сегмента в } \\
\text { подошве с центром на продольной оси рельса, хорда А-30мм, h-7мм }\end{array}$ & + & + \\
\hline $\begin{array}{c}\text { модель дефекта 99: коническое отверстие в шейке рельса, } \\
\text { геометрические размеры: Ø-2мм с рабочей грани, Ø-5мм с } \\
\text { нерабочей грани, h-105мм }\end{array}$ & + & + \\
\hline Выявляемость дефектов в \% 10 шт. & $\mathbf{7 0 \%}$ & $100 \%$ \\
\hline
\end{tabular}

- Способ, обеспечивает регистрацию разноориентированных отражателей.

- Способ применим вне зависимости от уровня техники и пригоден к промышленному применению и универсален в использовании с различными видами неразрушающего контроля при сплошном и ручном контроле.

Достоинством ЗЭТС ЭЛМ УЗК является:

- Регистрация разноориентированных отражателей за счёт реализации раздельного режима работы ПЭП и облучения отражателей различными углами «Q» и «k» УЗК на основе построения звукового коридора диаграмм направленностей, что позволяет компактно и рационально разместить ПЭП на поверхности сканирования (Рисунок № 4, 5). 
- применение множества ПЭП с различными углами « осуществить приём дублированных ЭС, что позволяет снизить зависимость амплитуды ЭС от ориентации;

- односторонний доступ позволяет использовать его при ручном и сплошном контроле съёмными и мобильными средствами НК при V-120км|ч.

Недостатками ЗЭТС ЭЛМ УЗК является:

- зависимость стабильности акустического контакта между рабочей поверхностью искательного блока и поверхностью катания головки рельса. Однако, и этот недостаток имеет свой решения.

Одним из таких решений является метод магнитной памяти металла, позволяющий решить задачу стабильности акустического контакта и контроля «скрытой зоны» для ультразвуковых методов при скоростном контроле рельсов. Сущность метода заключается в оценке фактического напряжённо-деформированного состояния работающих конструкций, чего в настоящее время при неразрушающем контроле рельсов, уложенных в путь, не делается. Метод основан на регистрации и анализе распределения собственных магнитных полей рассеивания на поверхности изделия, возникающих в зонах концентрации напряжений, дефектов, неоднородности структуры металла и сварных соединений. В методе используются естественная намагниченность и последствие, которое проявляется в виде магнитной памяти металла -последствия в виде остаточной намагниченности металла, сформировавшейся в процессе изготовления и охлаждения в магнитном поле Земли, или в виде необратимого изменения намагниченности изделий в зонах концентрации напряжений и повреждений от рабочих нагрузок [7].

Метод обладает следующими достоинствами и преимуществами:

- не требует какой-либо подготовки объекта контроля,

- используется естественная намагниченность изделия,

- датчики имеют малые габаритные размеры и автономное питание,

- позволяет производить раннюю диагностику усталостных повреждений и «преддефектного» состояния всего сечения рельса по всей его длине в том числе и «скрытой зоны», а в сочетании с другими видам НК позволит кадифицировать историю развития дефектов,

- метод применим в течение всего календарного года;

- метод позволяет в режиме экспресс-контроля определять с точностью до 1 мм зону концентрации напряжения, $[7,8]$.

Для повышения эффективности неразрушающего контроля рельсов при скоростном контроле мобильными средствами НК необходимо применение не только традиционных методов ультразвукового контроля, но и иных новых методов контроля.

Суммирующий эффект взаимодействия достоинств и преимуществ различных методов неразрушающего контроля рельсов, как применяемых в настоящее время, так и новых, характеризуется эффективностью, возрастающей в геометрической прогрессий, по сравнению с эффективностью каждого отдельного метода НК. Одними из таких новых методов и является Эхолокационного метода ультразвукового контроля изделия по всему сечению и Метод магнитной памяти металла способных дополнить систему контроля сварных рельсовых стыков в течение всего календарного года тем самым повысив его достоверность и эффективность. 
Реализация перечисленных выше достоинств повышает не только эффективность ультразвукового контроля рельсов, но и в целом системы обеспечивающей безопасность бесперебойных пассажирских и грузовых железнодорожных перевозок.

$$
* * *
$$

1. Конарев Н.С. Железнодорожный транспорт. Энциклопедия. - М: «Большая Российская энциклопедия». 1995. C.381

2. Кабардин О.Ф. Физика: Справ. материалы: Учеб. пособие для учащихся. - 3-е изд. - М.: Просвещение, 1991. C. 224-225.

3. Алёшин Н.П. Методы акустического контроля металлов. М.: Машиностроение, 1989. С.24-55.

4. Кретов Е.Ф. Ультразвуковая дефектоскопия в Энергомашиностроении. Учебное пособие - СПб.: «Радиоавионика», 1995. С. 159-161.

5. Погорелов А.В. Геометрия. Учебное пособие для 6-10 классов средней школы - М.: «Просвещение», 1985. C.82-83; 88-89.

6. НТД/ЦП-1-93 «Классификация дефектов рельсов», Министерство путей сообщения РФ Управление пути всероссийский научно-исследовательский институт железнодорожного транспорта, Издательство «Транспорт», Москва, 1993 год.

7. Дубов А.А., Дубов Ал.А., Колокольников С.М. Метод магнитной памяти металла и приборы контроля. Учебное пособие. Издание третье. - М: «Тиссо». 2006. С.3-24.

8. Дубов А.А. Метод магнитной памяти металла - диагностика XXI века. С.2-5.

9. ОАО РЖД Альбом изломов за 2009, 2010, 2011, 2012, 2013, 2014, 2015 г. (согласно п.2 дополнительных мероприятий по улучшению качества работы средств дефектоскопии в путевом хозяйстве железных дорог). Москва.

10. Патент 2442152 МПК G01N 29/04. Эхолокационный метод ультразвукового контроля по всему сечению/ Корепанов А.А., Князев Д.А. - Заявка №2010129458/28 от 16.07.2010. Опубликовано 10.02.2012. Бюл.№4.

11. Марков А.А. Шпагин Д.А., Ультразвуковая дефектоскопия рельсов. 2-е изд. Переработанное и дополненное - СПб.: «Образование - Культура». 2008. С. $39-42$.

Худовец В.И., Кузнецов Е.Е., Кузнецова О.А.

Гидравлически-прижимное разрыхляющее устройство в ходовой системе полурамного трактора

ФГБОУ ВО Дальневосточный ГАУ

(Россия, Благовещенск)

doi: 10.18411/sr-10-10-2017-05

idsp: 000001:sr-10-10-2017-05

\section{Аннотация}

Одним из способов снижения уплотнения почв по следу движения трактора является рациональное распределение массы трактора по его осям или дополнительное рыхление почв по следу движения колёсной системы.для решения проблемы предлагается способ снижения уплотнения почв колёсными движителями за счёт применения устройства, на которое получен патент на полезную модель.

Ключевые слова: плотность почвы, уплотнение почвы, колесные движители, трактор, дискаторный разуплотнитель следа полурамного трактора.

Изменение урожайности возделываемых культур зависит не только качества семенного материала, но и от сочетания природно-климатических и техногенных факторов, взаимодействующих в процессе растениеводства.

Несбалансированный отток поверхностных водс обрабатываемых агрофонов вследствие неудовлетворительного состояния мелиоративных систем, естественное природное переувлажнение в период проведения основных сельскохозяйственных работ, буксование движителей обрабатывающей колёсной техники и её многократный проход приводят к почвенному повреждению и формированию переуплотнённого поверхностного слоя, что в условиях зоны экстремального земледелия, к которой 